\title{
The effectiveness of workplace smoking cessation programmes: a meta-analysis of recent studies
}

\author{
G Smedslund, K J Fisher, S M Boles, E Lichtenstein
}

Tobacco Control 2004;13:197-204. doi: 10.1136/tc.2002.002915

See end of article for authors' affiliations

Correspondence to: Dr Geir Smedslund Directorate for Health and Social Affairs, Postboks 8054 Dep, NO-0031 Oslo, Norway; ges@shdir.no

Received 23 December 2002

Accepted 4 January 2004
Objective: Using meta-analytic procedures, we compare the effectiveness of recent controlled trials of worksite smoking cessation during the 1990s with a previous meta-analysis of programmes conducted in the 1980s.

Data sources: $\mathrm{ABI} /$ Inform, BRS, CHID, Dissertation Abstracts International, ERIC, Medline, Occupational Health and Safety Database, Psyclnfo, Smoking and Health Database, SSCI, and Sociological Abstracts. Study selection: Controlled smoking cessation interventions at the workplace with at least six months follow up published from 1989 to 2001 and reporting quit rates (QRs).

Data extraction: Two reviewers independently scanned titles/abstracts of relevant reports, and we reached consensus regarding inclusion/exclusion of the full text reports by negotiation. A third reviewer resolved disagreements. Two reviewers extracted data according to a coding manual. Consensus was again reached through negotiation and the use of a third reviewer.

Data synthesis: 19 journal articles were found reporting studies conforming to the study's inclusion criteria. Interventions included self help manuals, physician advice, health education, cessation groups, incentives, and competitions. A total of 4960 control subjects were compared with 4618 intervention subjects. The adjusted random effects odds ratio was 2.03 (95\% confidence interval 1.42 to 2.90 ) at six months follow up, $1.56(95 \% \mathrm{Cl} 1.17$ to 2.07$)$ at 12 months, and $1.33(95 \% \mathrm{Cl} 0.95$ to 1.87$)$ at more than 12 months follow up. Funnel plots were consistent with strong publication bias at the first two follow ups but not the third. In Fisher et al's 1990 study, the corresponding ORs were 1.18, 1.66, and 1.18.

Conclusions: Smoking cessation interventions at the worksite showed initial effectiveness, but the effect seemed to decrease over time and was not present beyond 12 months. Compared to the Fisher (1990) analysis, the effectiveness was higher for the six month follow up. Disappointingly, we found methodological inadequacies and insufficient reporting of key variables that were similar to those found in the earlier meta-analysis. This prevented us from determining much about the most effective components of interventions. It is advisable for researchers conducting studies in the future to report data on attrition and retention rates of participants who quit, because these variables can affect $Q R$ s.
$\mathrm{T}$ he workplace as a setting for smoking cessation research and intervention has several advantages. First, it provides access to a large number of people who make up a relatively stable population. Second, it has the potential for reaching a larger proportion of the smoking population than non-workplace environments. Third, worksites have the potential to provide sustained peer group support and positive peer influence for quitting and staying tobacco free. Fourth, it provides a particular opportunity to target young men, who traditionally have low general practitioner consultation rates and are thus less likely to benefit from opportunistic health promotion activity in primary care. Fifth, in selected workplaces, occupational health staff may be on hand to give professional support. Finally, the convenience of cessation opportunities and programmes onsite is a decided advantage to the employee. ${ }^{1}$

Reviews and evaluations of worksite health promotion and smoking control interventions in the 1990s abound, ${ }^{1-9}$ but more than a decade has passed since the most recent meta-analytic review of worksite smoking cessation was published. ${ }^{10}$ In that study, a weighted mean effect size of 0.21 from 34 comparisons (from 20 controlled studies) was found, which translated to an average quit rate (QR) in the intervention groups of 13\% for long term (average of 12 months) cessation. ${ }^{10}$ The 1990 study also identified a number of recommendations for future research in worksite cessation, particularly the need for improving methodological quality, including the need for reporting worksite-wide smoking prevalence and participation rates.

\section{Meta-analysis as a data integration strategy}

A meta-analysis is a quantitative synthesis of the results of many different studies of the same genre. Core advantages of meta-analysis are its ability to detect trends in a set of studies that may not be obvious to the naked eye, and to provide a quantitative estimate of the magnitude of effect. The outcome of a meta-analysis is known as an "effect magnitude". ${ }^{11}$ Effect magnitudes can be expressed and calculated in several ways, depending on the formation of the data; several publications have described more sophisticated methods for dealing with meta-analysis. ${ }^{12-15}$ The three most common types of effect magnitude are: (1) the standardised mean difference, called "effect size" or " $\mathrm{d}$ "; (2) the correlation coefficient $r$; and (3) the odds ratio (OR). In the present meta-analysis, we used the QRs in the experimental and control conditions to calculate ORs.

Several authors ${ }^{14-17}$ have identified deficiencies and problems with narrative literature reviews that meta-analysis can address: (1) selective inclusion of studies by the researcher based on impressions of study quality; (2) differential, subjective weighting of studies in the interpretation of study findings; (3) incorrect or misleading interpretation of study findings; (4) failure to identify the extent to which study characteristics confirm or refute consistent 
results across studies; and (5) failure to examine the influence of moderating variables on study outcomes.

Additionally, meta-analysis itself is subject to several criticisms, which fall into four broad categories ${ }^{18}{ }^{19}$ :

1. The "apples and oranges" problem. Diverse measuring instruments, different subjects, various treatments and outcomes, and other differences make meaningful comparisons illogical.

2. The use of data from "poor" studies. Meta-analysis procedures often uncritically accept poorly designed or low quality studies into the analysis, rendering aggregated solutions mediocre or uninterpretable.

3. Selection bias in favour of reported research. Published research is biased in favour of significant findings; thus, meta-analytic results are also biased.

4. Non-independent data. Multiple comparisons from large data sets that contribute to meta-analyses make the results seem more reliable than they really are.

In this study, these four issues were addressed in the following ways. The "apples and oranges" problem was dealt with empirically by coding possible moderator variables in each study according to predetermined criteria. This made it possible to investigate the degree to which these variables accounted for variance in the meta-analytic results. For smoking cessation studies, the dependent measure of QR is less problematic in terms of measurement criteria than in many other disciplines because it is a widely used criterion measure of outcome. Potential moderator variables that influence QR can be generated from published reviews of worksite smoking cessation and by examination of recent high quality studies.

The second criticism was addressed by adopting Slavin's ${ }^{16} 20$ "best evidence" synthesis, which gives priority to studies highest in internal and external validity based upon defended, well specified inclusion criteria developed after a thorough examination of the literature. In the present study, we judged that the best evidence came from studies with a control or comparison group and having a follow up time of at least six months. Although these two criteria do not guard against inclusion of low quality studies, they lower the probability of bias due to self selection and transitory effects of cessation programmes. Coding procedures were developed to accommodate possible variations in methodology across these best evidence studies.

The problem of potential bias in published studies ${ }^{21}$ was addressed by producing funnel plots. ${ }^{22}$ This is a graphical method for detecting the relative absence of small, imprecise studies with negative results.

In addressing the fourth criticism relating to the use of a large number of results from the same study, we selected only one comparison for each study. In the studies with more than one treatment group, we consistently compared the simplest treatment (or a no treatment control group) versus the next simplest treatment. Typically, the other groups received nested interventions with which there were problems with disentangling the active ingredients of the treatment. We ran separate analyses for six month follow up, 12 month follow up, and more than 12 month follow up. Each study could contribute a maximum of three effect magnitudes (three follow up time points), but only one effect size per study was allowed into any single analysis.

\section{METHODS}

\section{Inclusion criteria}

A thorough search of all published and unpublished studies on smoking cessation from January 1989 through December 2000 was conducted. For potential inclusion in our meta-analysis, studies had to conform to the following criteria: (1) a study of worksite smoking cessation that (2) reported QRs for a follow up of at least six months posttreatment, (3) included a control or comparison group, and (4) published between January 1989 and December 2000.

\section{Search strategies}

Electronic database searches were conducted, and review articles were consulted. A manual search of reference lists from retrieved publications was also conducted.

Search criteria- "Smoking cessation" was used as a subject descriptor with "worksite" or "work site" or "workplace." Studies appearing in publications from the years 1989 to 2000 were included.

Databases searched-We searched the following databases for studies that met the prescribed criteria: ABI/Inform, BRS, Combined Health Information Database (CHID), Dissertation Abstracts International Database, ERIC, Medline, Occupational Health and Safety Database, PsycInfo, Smoking and Health Database, Social Sciences Citation Index, and Sociological Abstracts Database.

\section{Selecting papers for coding}

Titles and abstracts provided the basis for initial decisions and selection of documents. Two raters independently scanned the set of documents for inclusion/exclusion criteria met by the titles and/or abstracts. The two raters then met and on the basis of relevance contained in the title or abstracts, agreed on a group of 109 full text reports that would be considered for coding. Each rater then made an independent decision on whether a paper met the inclusion criteria. Initially, 25 published articles were judged to meet the coding criteria, ${ }^{23-25} 27-48$ but after further consideration, six papers $^{23-25} 293145$ were excluded. One paper ${ }^{23}$ was excluded because it reported data that were already reported in one of the included papers. ${ }^{37}$ Two other papers ${ }^{24} 25$ employed workplace randomised designs and were excluded because they reported outcomes in the form of workplace prevalence rates and not individual level QRs. We elected to omit these from the meta-analysis but report their outcomes. Hence, a final set of 19 papers was coded using a coding manual adapted from Lipsey and Wilson. ${ }^{12}$ Inter-rater reliability was computed on the set of 25 studies.

\section{Coding variables}

Design variables - The coding variables based on study design included random or non-random assignment, unit of randomisation (subject or worksite), unit of analysis (subject or worksite), attrition, lost at follow up, biochemical verification, length of follow up, and pre-test group comparison.

Sample descriptors-The coding descriptors included age, race, sex, education, smoking rate (cigarettes/day), smoking prevalence, and previous quit attempts.

Organisation variables - These variables included company size, type of industry, private or public workplace setting, and stringency of nonsmoking policy. Whenever there were multiple sites in a study, we calculated an average company size or "typical" site (using the mode statistic).

Intervention descriptors-These descriptors included intervention type (self help, physician advice, incentives, cessation group, steering committee, and other), treatment duration (fixed time or intermittent), whether the intervention took place on company time, and whether the intervention was part of a larger programme.

Effect size data-These variables included control group n; treatment group n; QR for six months, 12 months, and/or more than 12 months; QR type (seven day point prevalence, 30 day point prevalence, or continuous abstinence). 


\section{Excluded randomised trials}

Two large trials were highly relevant to the present analysis but were not included in the meta-analysis because they estimated QRs indirectly from prevalence changes. Moskowitz et $a l^{24}$ estimated the effects of local workplace smoking laws in California. They found that smokers who worked in localities with a strong workplace ordinance (compared with no workplace ordinance) were more likely to report quitting smoking in the prior six months (OR 1.5, 95\% confidence interval (CI) 1.1 to 1.7 ).

Sorensen $e t a^{25}$ presented results of the Working Well Trial, the largest worksite cancer prevention and control trial to date in the USA. The Working Well Trial used a randomised, matched pair evaluation design, with the worksite as the unit of assignment and analysis. The study was conducted in 111 worksites ( $\mathrm{n}=28000$ workers). The effects of the intervention were evaluated by comparing changes in intervention and control worksites, as measured in cross sectional surveys at baseline and follow up. The two year intervention targeted both individuals and the worksite environment. Changes in tobacco use were in the desired direction but were not significant.

\section{ANALYSIS}

The 19 controlled trials in this review may be considered a "best evidence"16 subset of the literature on the topic and, as such, are well suited to meta-analytic procedures. Each of the studies was cast into a short term ( six month QR), intermediate term (12 month QR), or long term (more than 12 months QR) frequency table based on the count of smokers and quitters in treatment and control conditions at each assessment point. The number of quitters and the total number of participants was recorded in Review Manager $4.2,{ }^{26}$ which is the Cochrane Collaboration's software for meta-analysis. A random effects model was used, assuming that the effect magnitudes come from a distribution of true effect magnitudes and not a single true magnitude. The effect magnitudes were weighted by the standard error of their natural logarithms, and a 95\% CI was computed.

\section{RESULTS}

The studies in the present analysis are mutually exclusive of the studies in Fisher et al's ${ }^{10}$ analysis. Table 1 offers an overview of the setting, design, and intervention of the included studies. ${ }^{27} 280^{32-44} 46-48$ The sample size in the 19 included studies ranged from 56 to 2317, with a median of 426.5. Nine studies were randomised trials. All but three $e^{27} 3943$ reported follow up times of at least 12 months. As table 1 shows, the papers report a high degree of diversity regarding intervention types, settings, and participants. Types of interventions coded were bibliotherapy (that is, self help written materials) (16 studies), cessation group (13 studies), "other type" (12 studies), incentives (nine studies), steering committee (seven studies), non-smoking policy (four studies), physician advice (two studies), and pharmacological treatment (two studies).

\section{Inter-rater reliability}

Initially, we coded the 25 studies that made the final cut in terms of satisfying the inclusion criteria as a pilot practice. The mean inter-rater reliability for this pilot coding was $72 \%$. Any disagreements related to the pilot coding procedures and the decision to reduce the final set of studies to 19 was resolved through a third reviewer (EL). For the final set of 19 studies the two raters (GS and KJF) achieved 100\% agreement.
Results and reporting of moderator variables

All included studies were published articles in peer reviewed journals. Some dissertations qualified for inclusion initially, but were later excluded because the results appeared in a subsequent published article. Some studies were conducted in a number of different sites. Company size was coded by using the average number of workers at each site. One study had fewer than 100 employees per site, three had between 100-249 employees, three had between 250-750 employees, and 11 had more than 750 employees at the typical site. One study did not report data on number of employees. Six worksites were coded as "manufacturing/construction", two were coded as "utilities/transport/communication", three were coded as "service/educational/hospital", six were coded as "mixed", one was coded as "other", and one had missing data on this variable. Seven worksites were private, five were public, five were mixed, and two had missing data. Two worksites had no smoking policy, two allowed smoking in separate areas, none had a total ban, and the remaining 12 did not report stringency of non-smoking policy. Four studies reported that smoking cessation was part of a larger programme to improve health. Small sample sizes prevented us from conducting meaningful sub-analyses of effects of most moderator variables.

Among methodological characteristics, attrition during the intervention was reported in only six of the 19 studies and participants lost at follow up were reported in only seven studies. Twelve studies reported some kind of biochemical validation of smoking abstinence, while seven studies did not. Thirteen studies had interventions that lasted a fixed time. In six studies, the interventions were intermittent, meaning that cessation programmes or activities were implemented at certain times rather than being regularly accessible.

\section{Quit rates}

Table 2 shows quit rates for each study, group and follow up. For example, the first study (Bertera 1990) reported only data for more than 12 months, while the Jason 1997 study reported data on all three follow up points. The variation in the quit rates is tremendous in the intervention groups for all follow ups. The variation is also large in the control groups.

Table 3 provides data on characteristics and reporting on some of the other moderator variables. Most studies have been conducted in workplaces with high smoking prevalence and with white, heavy smokers. Possible important moderator variables, such as previous quit attempts, cigarettes per day, and education level, were inconsistently reported.

\section{Odds ratios and quit rates}

For each study, we recorded data on up to three independent treatment conditions and at three time points (42 effects sizes), but since only 11 effect sizes came from a second or third treatment condition, we elected to focus mainly on one treatment condition for each study (the two simplest conditions). Hence, most of the reported analyses were restricted to $28 \mathrm{QRs}$ (table 2). The weighted ORs were 2.03 ( $95 \%$ CI 1.42 to 2.90 ), 1.56 (95\% CI 1.17 to 2.07 ), and 1.33 (95\% CI 0.95 to 1.87 ) for the three follow up points, respectively (figs 1-3). At six months the overall QR was $16.7 \%$ in the intervention groups versus $8.5 \%$ in the control groups, at 12 months it was $20.8 \%$ versus $12.2 \%$, and at more than 12 months it was $17.2 \%$ versus $13.9 \%$.

\section{Randomised and non-randomised studies}

Figure 1 shows a forest plot of the six month follow up. The studies are divided into randomised and non-randomised. The non-randomised show a much stronger effect (OR 4.65) than the randomised ones (OR 1.74). The precision of the 
Table 1 Characteristics of evaluations of worksite smoking cessation programmes ( $n=19$ studies)

\begin{tabular}{|c|c|c|c|c|c|}
\hline Study & $\begin{array}{l}\text { Sample } \\
\text { size }\end{array}$ & Setting and comparison tested & $\begin{array}{l}\text { Company } \\
\text { size }\end{array}$ & $\begin{array}{l}\text { Random } \\
\text { allocation }\end{array}$ & $\begin{array}{l}\text { Follow up } \\
\text { (months) }\end{array}$ \\
\hline Bertera $1990^{27}$ & 70 & Stop smoking clinic versus self-help kit. ALA "Freedom From Smoking" & $>750$ & No & $>12$ \\
\hline Burling $1989^{28}$ & 58 & VA Medical Center employees. Computerised nicotine fading versus contest only & NR & Yes & 6 \\
\hline Erfurt $1991^{30}$ & 671 & $\begin{array}{l}\text { Manufacturing plants. Health education, counselling, social organisation. } \\
\text { Screening + health education versus screening only }\end{array}$ & $>750$ & No & $>12$ \\
\hline Glasgow $1993^{32}$ & 512 & Stop smoking contest. Incentive versus no incentive & $250-750$ & No & $>12$ \\
\hline Glasgow $1995^{33}$ & 431 & $\begin{array}{l}\text { Take Heart Study. } 26 \text { worksites in Oregon. Steering committee and menu } \\
\text { approach. Early intervention versus delayed intervention }\end{array}$ & $100-249$ & Yes & $>12$ \\
\hline Gomel $^{42}$ & 431 & $\begin{array}{l}28 \text { ambulance stations in Sydney, Australia. Counselling. Risk factor education } \\
\text { versus health risk assessment }\end{array}$ & $<100$ & Yes & 6,12 \\
\hline Helyer $1998^{35}$ & 104 & Air Force smoking cessation groups versus no treatment & $<100$ & No & 6,12 \\
\hline Hymowitz $1991^{36}$ & 252 & $\begin{array}{l}\text { Smoking cessation, health education, worksite non-smoking policy. Group + } \\
\text { enriched milieu versus group only }\end{array}$ & $>750$ & Yes & 12 \\
\hline Jason $1997^{37}$ & 844 & $\begin{array}{l}\text { Worksite television program, newspaper, support groups. Self help manual + } \\
\text { incentives versus manual only }\end{array}$ & $100-249$ & Yes & $6,12,>12$ \\
\hline Koffman $1998^{38}$ & 177 & $\begin{array}{l}\text { Aerospace industry. Multicomponent programme (self help, telephone, } \\
\text { incentives) versus standard smoking cessation }\end{array}$ & $>750$ & No & 6,12 \\
\hline Lang $2000^{39}$ & 1269 & $\begin{array}{l}\text { Electrical and gas company. Contract, quit date }+ \text { follow up support by } \\
\text { worksite physician versus simple advice to quit }\end{array}$ & $100-249$ & Yes & 6,12 \\
\hline Maheu $1989^{40}$ & 56 & Nicotine gum. Group treatment + competition versus group only & $>750$ & No & 6 \\
\hline Muto $1998^{41}$ & 70 & Chemical company. "Smoke Busters." Six workshop sessions versus control & $>750$ & No & 12 \\
\hline Olsen $1991^{42}$ & 2317 & $\begin{array}{l}\text { Dow Chemical Texas Operations. Smoking Cessation Incentive Program (SCIP) } \\
\text { versus control }\end{array}$ & $>750$ & No & $>12$ \\
\hline Salina $1994^{43}$ & 419 & $\begin{array}{l}38 \text { Chicago companies. Self help manuals, television, quitting techniques, social } \\
\text { support versus manuals and television only }\end{array}$ & $100-249$ & Yes & $6,12,>12$ \\
\hline Sorensen $1993^{44}$ & 681 & Consultation. Cessation classes versus control & $>750$ & Yes & 6 \\
\hline Willemsen $1995^{46}$ & 394 & $\begin{array}{l}\text { Dutch telecommunications company. Tailored letter of advice, } \\
\text { self help guide, group cessation, telephone quit line versus control }\end{array}$ & $>750$ & No & 12 \\
\hline Willemsen $1999^{47}$ & 498 & Enriched environment versus control & $250-750$ & No & $>12$ \\
\hline Willemsen $1998^{48}$ & 438 & $\begin{array}{l}\text { Self help manual, group, mass media, smoking policies versus } \\
\text { self help manual only }\end{array}$ & $>750$ & No & $>12$ \\
\hline
\end{tabular}

estimates is greater for the randomized studies (95\% CI 1.26 to 2.40 ) than for the non-randomised ones (95\% CI 1.92 to 11.28). The $\chi^{2}$ test for homogeneity confirmed that both types of studies show homogeneity at the six month follow up. The funnel plot shows strong evidence of publication bias.

Figure 2 shows similar results for the 12 month follow up. The effects have decreased for both types of study and the precision is greater for the randomised studies. Both subgroups are homogenous and there is strong evidence for publication bias.

Figure 3 shows that the effects do not seem to last beyond 12 months as evidenced by confidence intervals for the total group and both subgroups surrounding 1 . The set of randomised studies is homogenous, but the non-randomised ones are heterogeneous. There is no evidence for publication bias, except for the small Bertera 1990 study.

\section{Comparison of the 1990 and 2001 surveys}

The overall ORs found in the present study $(2.03,1.56,1.33$ at 6,12 , and $>12$ months) is quite similar to the corresponding ORs of 1.18, 1.66, and 1.18 found in the Fisher et al study. In 1990, 34 comparisons produced an overall QR of 13\% in the intervention groups. In the 2001 analysis, 28 comparisons produced a QR of around $18 \%$.

Table 2 Quit rates at different follow up points for the selected conditions ( $n=19$ studies)

\begin{tabular}{|c|c|c|c|c|c|c|}
\hline \multirow[b]{2}{*}{ Study } & \multicolumn{2}{|c|}{6 month quit rate $(\%)$} & \multicolumn{2}{|c|}{12 month quit rate (\%) } & \multicolumn{2}{|c|}{$>12$ month quit rate (\%) } \\
\hline & Intervention & Control & Intervention & Control & Intervention & Control \\
\hline Bertera $1990^{27}$ & & & & & 20.9 & 11.1 \\
\hline Burling $1989^{28}$ & 21.4 & 11.5 & & & & \\
\hline Erfurt $1991^{30}$ & & & & & 10.5 & 16.7 \\
\hline Glasgow $1993^{32}$ & & & 10.8 & 11.6 & 14.2 & 11.5 \\
\hline Glasgow $1995^{33}$ & & & & & 25.0 & 27.0 \\
\hline Gomel $1993^{42}$ & 10.0 & 1.0 & 7.0 & 0.0 & & \\
\hline Helyer $1998^{35}$ & 30.8 & 8.1 & 23.1 & 6.5 & & \\
\hline Hymowitz $1991^{36}$ & & & 18.0 & 22 & & \\
\hline Jason $1997^{37}$ & 10.3 & 4.3 & 10.0 & 7.5 & 13.2 & 10.3 \\
\hline Koffman $1998^{38}$ & 23.0 & 8.0 & 30.0 & 11.0 & & \\
\hline Lang $2000^{39}$ & 6.1 & 4.6 & 18.4 & 13.5 & & \\
\hline Maheu $1989^{40}$ & & & 50.0 & 25.0 & & \\
\hline Muto $1998^{41}$ & & & 22.9 & 5.7 & & \\
\hline Olsen $1991^{42}$ & & & & & 7.5 & 2.8 \\
\hline Salina $1994^{43}$ & 28.9 & 19.1 & 29.1 & 23.4 & 30.0 & 19.5 \\
\hline Sorensen $1993^{44}$ & 12.0 & 8.9 & & & & \\
\hline Willemsen $1995^{46}$ & & & 9.0 & 8.0 & & \\
\hline Willemsen $1998^{48}$ & & & & & 16.0 & 12.0 \\
\hline Willemsen $1999^{47}$ & 7.5 & 11.1 & & & & \\
\hline Unweighted mean & 16.7 & 8.5 & 20.8 & 12.2 & 17.2 & 13.9 \\
\hline Range & $6.1-30.8$ & $1.0-19.1$ & $7.0-50.0$ & $0.0-25.0$ & $7.5-30.0$ & $2.8-27.0$ \\
\hline
\end{tabular}




\begin{tabular}{|c|c|c|}
\hline Variable & Mean/\% & Number missing \\
\hline Age & 39.8 & 2 \\
\hline Race & 12 white $/ 1 \mathrm{mixed} / 1$ other & 5 \\
\hline Males & $63.8 \%$ & 1 \\
\hline Education & 8 with some college/ 2 with no college & 9 \\
\hline Cigarettes per day & 22.4 & 6 \\
\hline Smoking prevalence & $29.3 \%$ & 5 \\
\hline Previous quit attempts & 3.0 & 18 \\
\hline Randomisation & 10 random $/ 9$ not random & 0 \\
\hline
\end{tabular}

\section{DISCUSSION}

The retrieval of 19 controlled studies of worksite smoking cessation interventions from the decade covering the 1990s was a similar yield to a previous meta-analysis ${ }^{10}$ of 20 studies covering the decade from the 1980s, and similar results were obtained ( 19 studies with 28 observations in 2001 versus 20 studies with 34 observations in 1990). The studies in the 1990s were almost twice as effective at the six months follow up as the studies in the 1980s, but this difference did not last at longer follow up points. Because we used the conservative strategy of consistently comparing the control group with the least comprehensive intervention arm, the effects may be somewhat underestimated-but at least this made the results more interpretable.

Review: Smoking cessation in the workplace

Comparison: 6 month follow up

Outcome: Randomised versus non randomised studies



Review: Smoking cessation in the workplace

Comparison: 6 month follow up

Outcome: Randomised versus non randomised studies

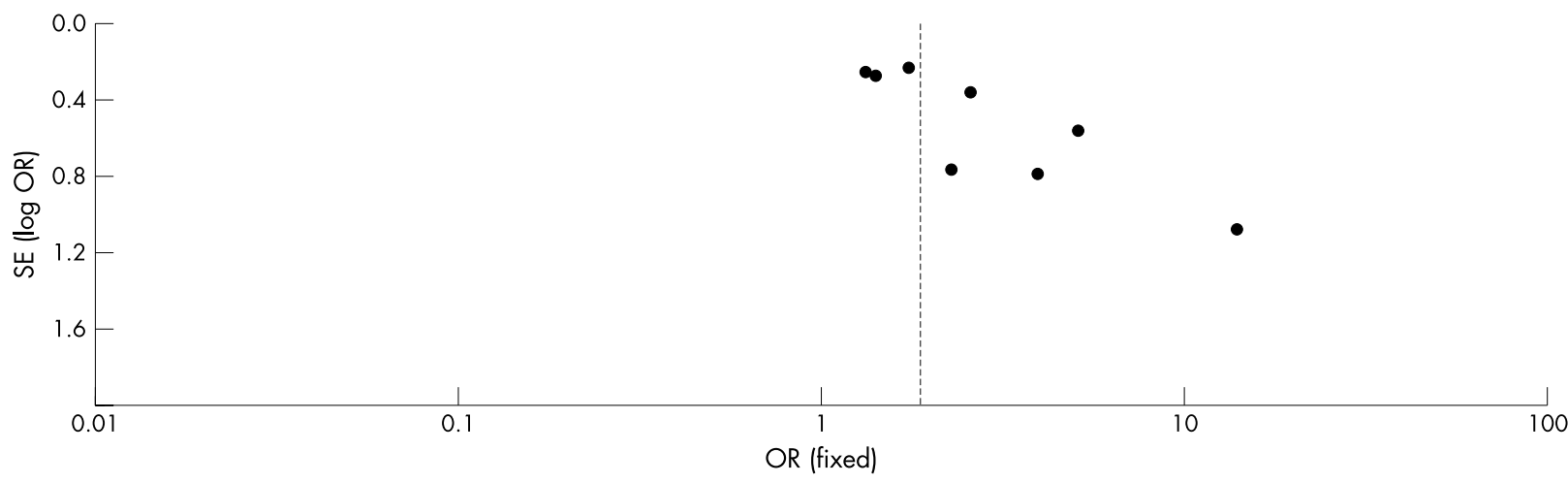

Figure 1 Upper panel: six months follow up data stratified into randomised and non-randomised studies. Lower panel: funnel plot of the odds ratios versus the standard error of the logged odds ratio. 
Review: Smoking cessation in the workplace

Comparison: 12 month follow up

Outcome: Randomised versus non randomised studies



Review: Smoking cessation in the workplace

Comparison: 12 month follow up

Outcome: Randomised versus non randomised studies

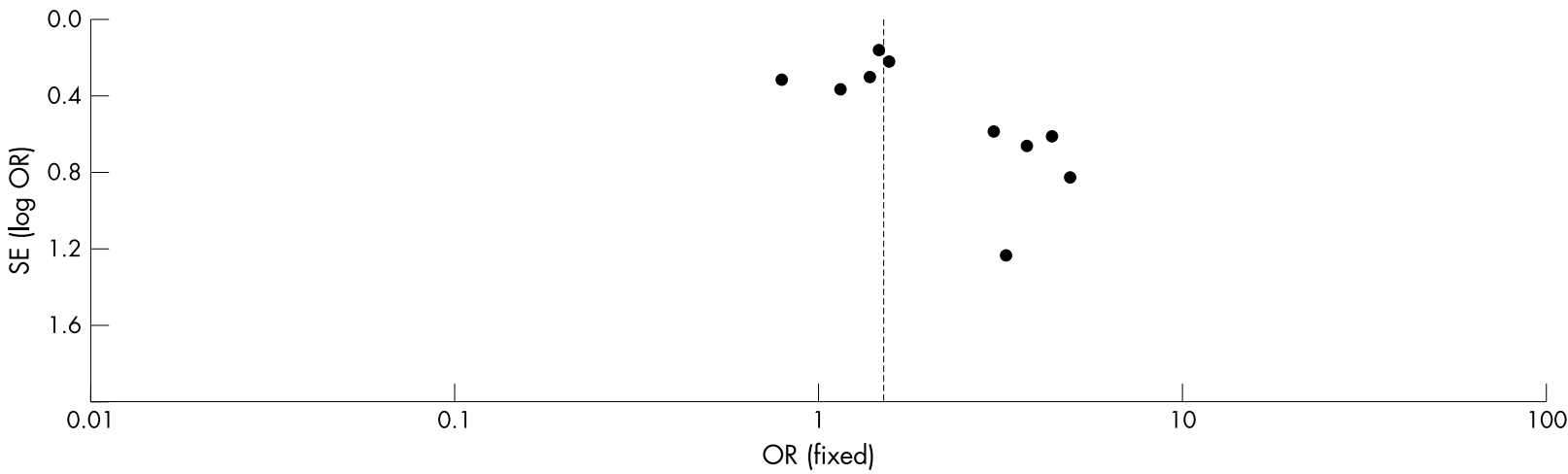

Figure 2 Upper panel: 12 months follow up data stratified into randomised and non-randomised studies. Lower panel: funnel plot of the odds ratios versus the standard error of the logged odds ratio.

Because we included both randomised and non-randomised studies, we were able to assess the effect of randomisation on the dependent variable. At all three follow up points, the non-randomised studies showed larger effects. This is consistent with the earlier meta-analysis, where quasi-designed studies had the largest effect sizes. ${ }^{10}$ The randomised results are probably closer to the truth, as the non-randomised studies are probably overestimating the effects. Because of the probable publication bias, we believe that the randomised studies are also overestimating the effects to some degree.

We collected a number of possible moderator variables for this study. However, because of the low number of observations, we did not find it feasible to do any meaningful subgroup analyses. The effects based on moderator variables were examined on three time points and on two methodological subgroups (randomised/non-randomised).
In the period covered by the present analysis, nicotine replacement therapies and other pharmacological treatments became increasingly popular. It is surprising that this trend did not show up more often as a treatment condition in studies. One reason might be that most pharmacological treatments for smoking cessation (for example, patches, gum) did not become over-the-counter medications until the late 1990s. Another reason might be that researchers excluded employers who confessed to using such medications.

Why did the results not improve even more over the decade of the 1990s? Not only did many new medications become more widely available and affordable, but there were also more restrictions on worksite smoking, and smokers were generally more marginalised in the work place as well as in society. These factors possibly contribute to the proportion of committed, "hard core" smokers who may be less motivated to quit and more likely to be nicotine dependent. 

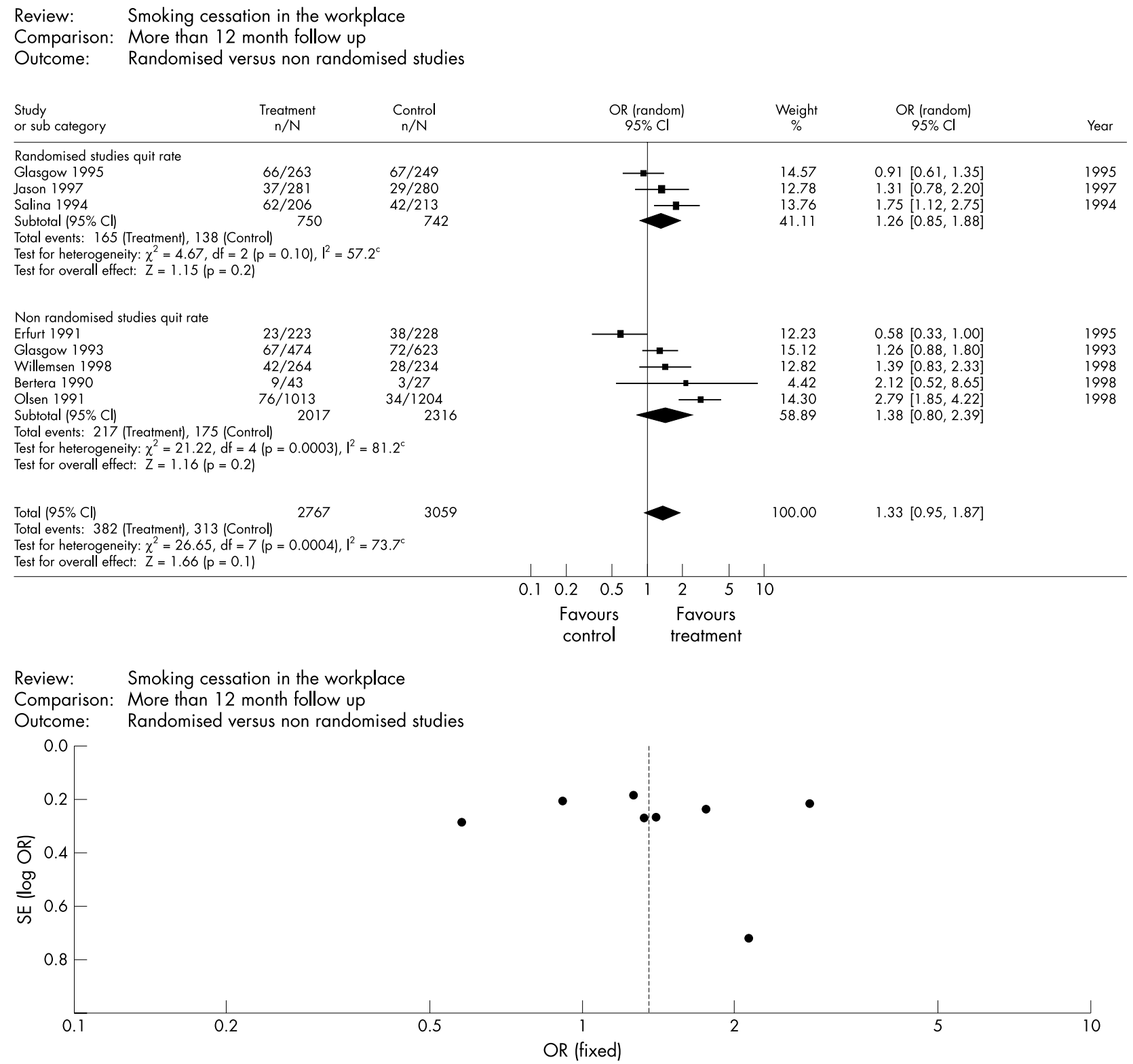

Figure 3 Upper panel: More than 12 months follow up data stratified into randomised and non-randomised studies. Lower panel: funnel plot of the odds ratios versus the standard error of the logged odds ratio.

Smoking cessation is influenced not only by the cessation programmes but also by the workplace settings and organisational context. These broader features and influences are also important to consider in relation to interpreting the results.

A possible source of bias in worksite intervention rises when the unit of randomisation differs from the unit of analysis. Eight studies ${ }^{31-33} 3536384243$ used the worksite as the unit of randomisation. In all but one $e^{31}$ of these studies, the analysis took into account the amount of intracluster correlation. Failing to do so may inflate the observed differences between groups.

We acknowledge some limitations to our study. First, this analysis included only studies published in English. From our electronic searches, however, there were few non-English research publications on worksite smoking cessation. This may have been because they were either unpublished or were published in journals not indexed in the databases we searched.
Although many studies of workplace smoking cessation were published during the 1990s (our initial pool of references cited 114 reports), a sizeable proportion had similar methodological or design inadequacies that were identified in Fisher et al's ${ }^{10}$ previous meta-analysis. Although the autonomy, resource limitations, and independence of researchers are respected, unless there is some conformity and consistency in reporting key variables, including design, type of industry, and key employee characteristics, generalisability of findings will be severely limited. Since the publication of the 1990 meta-analysis, the CONSORT statement (consolidated standards of reporting trials) has become available. ${ }^{49} 50$ The CONSORT contains a 21 item checklist and a flow diagram. The format provides readers with consistency from report to report as to where they can expect to find relevant information. It would be highly valuable if future authors use the CONSORT checklist when preparing primary reports. 


\section{What this paper adds}

The only previous published meta-analysis of the effects of worksite smoking cessation programmes covered the period until 1989. This meta-analysis adds data from the period 1989 to 2001 and compares the results of the two metaanalyses.

\section{ACKNOWLEDGEMENTS}

We thank Elizabeth Mondulick and Ron Renchler from Oregon Research Institute for helping in the preparation of this manuscript, and the anonymous reviewers who made valuable suggestions during the review process.

\section{Authors' affiliations}

G Smedslund, Directorate for Health and Social Affairs, Oslo, Norway K J Fisher, S M Boles, E Lichtenstein, Oregon Research Institute, Eugene, Oregon, USA

\section{REFERENCES}

Studies included in the meta-analysis marked by *.

Excluded studies marked by $\dagger$.

1 Moher M, Hey K \& Lancaster T. Workplace interventions for smoking cessation, Issue 3, 2003. Oxford, Update Software, 2003:1-59.

2 Eriksen MP, Gottlieb NH. A review of the health impact of smoking control at the workplace. Am J Health Promot 1998;13:83-104.

3 Matson D-M, Lee JW, Hopp JW. The impact of incentives and competitions on participation and quit rates in worksite smoking cessation programs. Am J Health Promot 1993;7:270-80.

4 Perry G. Jr. Workplace tobacco interventions. Indiana Med 1996;89:157-9.

5 Fielding JE. Smoking control at the workplace. Ann Rev Public Health $1991 ; 12: 209-34$.

6 Lusk SL. Health promotion and disease prevention in the worksite. Ann Rev Nurs Res 1997;15:187-213.

7 Harden A, Peersman G, Oliver S, et al. A systematic review of the effectiveness of health promotion interventions in the workplace. Occup Med (Lond) 1999:49:540-8.

8 Pelletier KR. Clinical and cost outcomes of multifactorial, cardiovascular risk management interventions in worksites: a comprehensive review and analysis. J Occup Environ Med 1997;39:1154-69.

9 Heaney CA, Goetzel RZ. A review of health-related outcomes of multicomponent worksite health promotion programs. Am J Health Promot 1997;11:290-307.

10 Fisher KJ, Glasgow RE, Terborg JR. Work site smoking cessation: a metaanalysis of long-term quit rates from controlled studies. J Occup Med 1990:32:429-39.

11 Hedges LV. How hard is hard science, how soft is soft science: the empirical cumulativeness of research. Am Psychol 1987;42:443-55

12 Lipsey MW, Wilson DB. Practical meta-analysis. Thousand Oaks, London, New Delhi: Sage Publications, 2001. (Applied Social Research Methods Series; 49).

13 Cooper H, Hedges LV. The handbook of research synthesis. New York: Russell Sage Foundation, 1994.

14 Hedges LV, Olkin I. Statistical methods for meta-analysis. Boston: Academic Press, 1985.

15 Bangert-Drowns RL, Wells-Parker E, Chevillard I. Assessing the methodological quality of research in narrative reviews and meta-analyses. In Bryant KJ, Windle M, West SG, eds. The science of prevention: methodological advances from alcohol and substance abuse research. Washington DC: American Psychological Association, 1997:405-29.

16 Slavin RE. best-evidence synthesis: an alternative to meta-analytic and traditional reviews. Educ Res 1986;15:5-11.

17 Rosenthal R, Dimatteo MR. Meta-analysis: recent developments in quantitative methods for literature reviews. Ann Rev Psychol 2001;52:59-82.

18 Glass GV, McGaw B, Smith ML. Meta-analysis in social research. Beverly Hills, California: Sage, 1981

19 Sharpe D. Of apples and oranges, file drawers and garbage: why validity issues in meta-analysis will not go away. Clin Psychol Rev 1997;17:881-901.

20 Slavin RE. Best-evidence synthesis: why less is more. Educ Res 1987;16:15-16.
21 Rosenthal R. The "file drawer problem" and tolerance for null results. Psychol Bull 1979;86:638-41.

22 Ferrer RL. Graphical methods for detecting bias in meta-analysis. Family Med 2003:30:579-83.

23 †Jason LA, McMahon SD, Salina D, et al. Assessing a smoking cessation intervention involving groups, inventives, and self-help manuals. Behav Ther 1995;26:393-408.

24 TMoskowitz J, Lin Z, Hudes E. The impact of workplace smoking ordinances in california on smoking cessation. Am J Pub Health 2000;90:757-61.

25 tSorensen G, Thompson B, Glanz K, et al. Work site-based cancer prevention: primary results from the Working Well Trial. Am J Pub Health 1996:86:939-47.

26 Review Manager (RevMan) [Computer program]. Version 4.2 for Windows. Oxford, England: The Cochrane Collaboration, 2003.

27 *Bertera RL, Oehl LK, Telephak JM. Self-help versus group approaches to smoking cessation in the workplace: eighteen-month follow-up and cost analysis. Am J Health Promot 1990;4:187-92.

28 *Burling TA, Marotta J, Gonzales R, et al. Computerized smoking cessation program for the worksite: treatment outcome and feasibility. J Consult Clin Psychol 1989;57:619-22.

29 †Conrad KM, Campbell RT, Edington D, et al. The worksite environment as a cue to smoking reduction. Res Nurs Health 1996;19:21-31.

30 *Erfurt J, Foote A, Heirich M. Worksite wellness programs: incremental comparison of screening and referral alone, health education, follow-up counseling, and plant organization. Am J Health Promot 1991;5:438-48.

31 tGlasgow R, Cummings KM, Hyland A. Relationship of worksite smoking policy to changes in employee tobacco use: findings from COMMITT. Tobacco Control 1997;6:44-8.

32 *Glasgow RE, Hollis JF, Ary DV, et al. Results of a year-long incentives-based worksite smoking cessation program. Add Behav 1993;18:455-64.

33 *Glasgow R, Terborg J, Hollis J, et al. Take heart: results from the initial phase of a work-site wellness program. Am J Public Health 1995;85:209-16.

$34{ }^{*}$ Gomel M, Oldenburg B, Simpson JM, et al. Work-site cardiovascular risk reduction: a randomized trial of health risk assessment, education, counseling, and incentives. Am J Public Health 1993;83:1231-8.

35 *Helyer AJ, Brehm WT, Gentry NO, et al. Effectiveness of a worksite smoking cessation program in the military. Program evaluation. Am Ass Occup Health Nurs 1998;46:238-45.

36 *Hymowitz N, Campbell K, Feuerman M. Long-term smoking intervention at the worksite: effects of quit-smoking groups and an "enriched milieu" on smoking cessation in adult white-collar employees. Health Psychol 1991;10:366-9.

37 *Jason LA, Salina D, McMahon SD, et al. Worksite smoking intervention: a 2 -year assessment of groups, incentives and self-help. Health Educ Res 1997; 12:129-38.

38 *Koffman DM, Lee JW, Hopp JW, et al. The impact of including incentives and competition in a workplace smoking cessation program on quit rates. Am J Health Promot 1998;13:105-11.

39 *Lang T, Nicaud V, Slama K, et al. Smoking cessation at the workplace: results of a randomised controlled intervention study. J Epidemiol Community Health 2000;54:349-54

40 *Maheu MM, Gevirtz RN, Sallis JF, et al. Competition/cooperation in worksite smoking cessation using nicotine gum. Prev Med 1989;18:867-78.

41 * Muto T, Nakamura M, Oshima A. Evaluation of a smoking cessation program implemented in the workplace. Ind Health 1998;36:368-71.

42 *Olsen GW, Lacy SE, Sprafka JM, et al. A 5-year evaluation of a smoking cessation incentive program for chemical employees. Prev Med 1991;20:774-84.

43 *Salina D, Jason LA, Hedeker D, et al. Follow-up of a media-based, worksite smoking cessation program. Am J Community Psychol 1994;22:257-71.

44 *Sorensen G, Lando H, Pechacek TF. Promoting smoking cessation at the workplace. results of a randomized controlled intervention study. J Occup Med 1993;35:121-6.

45 †Stave GM, Jackson GW. Effect of a total work-site smoking ban on employee smoking and attitudes. J Occup Med 1991;33:884-90.

46 *Willemsen MC, De Vries H. Evaluation of a smoking cessation intervention for Dutch employees consisting of self help methods and a group programme. Tobacco Control 1995;4:351-4.

47 *Willemsen MC, De Vries H, Oldenburg B, et al. Impact of a comprehensive worksite smoking cessation programme on employees who do not take part in cessation activities. Psychol Health 1999;14:887-95

48 *Willemsen MC, De Vries H, van Breukelen G, et al. Long-term effectiveness of two Dutch worksite smoking cessation programs. Health Educ Behav 1998;25:418-35.

49 Altman DG. Better reporting of randomised controlled trials: the CONSORT statement. BMJ 1996;313:570-1.

50 Begg C, Cho M, Eastwood S, et al. Improving the quality of reporting of randomized controlled trials. The CONSORT statement. JAMA 1996;276:637-39. 